\title{
HUBUNGAN KADAR PLUMBUM (Pb) DI UDARA LINGKUNGAN KERJA DENGAN KEJADIAN HIPERTENSI PADA OPERATOR STASIUN PENGISIAN BAHAN BAKAR UMUM (SPBU KARYA 14.)
}

\section{RELATIONSHIP OF PLUMBUM LEVELS (Pb) IN THE AIR WORK ENVIRONMENT WITH HYPERTENSION EVENTS IN OPERATORS OF FILLING GENERAL FUELS (SPBU KARYA 14.)}

\author{
Lia Rosa Veronika Sinaga ${ }^{1}$, Seri Asnawati Munthe ${ }^{2}$, Ronni Naudur Siregar ${ }^{3}$, Melvinnaria \\ Zamili $^{4}$ \\ ${ }^{1}$ Sari Mutiara University, Jalan Malinda, Kota Serdang Bedagai, 20986, Indonesia \\ ${ }^{2}$ Sari Mutiara University, Jalan Sekolah, Kota Deli Serdang, 20351, Indonesia \\ ${ }^{3}$ Sari Mutiara University, Jalan Pantai Timur, Kota Medan, 20126, Indonesia \\ ${ }^{4}$ Sari Mutiara University \\ Koresponding Penulis: ${ }^{1}$ liarosav@yahoo.com, ${ }^{2}$ serimunthe@yahoo.co.id, ${ }^{3}$ ronninaudursiregar85@gmail.com
}

\begin{abstract}
Abstrak
Timbal $(\mathrm{Pb})$ adalah logam atau salah satunya ditemukan dalam cat yang digunakan sebagai bahan pigmen warna. Timbal memiliki efek akut pada tekanan darah dan menyebabkan hipertensi karena paparan timbal yang berlebihan. Tujuan dari penelitian ini adalah untuk mengetahui hubungan antara kadar $\mathrm{Pb}$ di udara di lingkungan kerja dengan hipertensi di Operator Operator SPBU 14.201.145. Penelitian ini merupakan penelitian analitik dengan metode kuantitatif, dengan desain penelitian cross sectional untuk mengetahui hubungan. Sampel penelitian sebanyak 31 responden diambil dari total populasi (total sampling), pemeriksaan kadar timbal di udara di lingkungan kerja dilakukan oleh petugas Medan Riset dan Standardisasi Industri (Baristand) dan tekanan darah dilakukan oleh peneliti. Hasil penelitian adalah sebanyak $61,3 \%$ responden berada di lingkungan SPBU dengan kadar abnormal $(\mathrm{Pb})$ (> $2 \mathrm{~g} / \mathrm{m} 3)$, 38,7\% yang bertugas di lingkungan pompa bensin yang memiliki kadar normal $(\mathrm{Pb})$, secara keseluruhan tidak memiliki hipertensi. Sementara itu, dari 61,3\% yang bertugas di SPBU Karya yang memiliki kadar abnormal $(\mathrm{Pb})(>2 \mathrm{~g} / \mathrm{m} 3)$ ada mayoritas responden yang hipertensi sebanyak 41,9\% sedangkan 19,4\% lainnya melakukan tidak memiliki riwayat hipertensi. Diperoleh nilai $p=0,000(p<0,05)$, yang menunjukkan bahwa ada hubungan antara kadar $\mathrm{Pb}$ di udara Lingkungan Kerja Petugas Operator dan Kejadian Hipertensi di Stasiun Kerja. Pekerja harus menggunakan alat pelindung diri (APD) yang tepat saat bekerja dan mengurangi merokok untuk menghambat penyerapan timah.
\end{abstract}




\title{
Kata Kunci: Kadar Plumbum di Udara, Hipertensi, SPBU Karya
}

\begin{abstract}
Lead $(\mathrm{Pb})$ is a metal or one of which is found in paint that is used as a color pigment material. Lead has an acute effect on blood pressure and causes hypertension due to excessive lead exposure. The purpose of this study is to determine the relationship between the levels of $\mathrm{Pb}$ in the air in the work environment with hypertension in the SPBU Operator Operator 14.201.145. This research is an analytical study with quantitative methods, with cross sectional research design and analyzed using chi square test to determine the relationship. The research sample of 31 respondents was taken from the total population (total sampling), the examination of lead levels in the air in the work environment was carried out by Medan Research and Standardization Industry (Baristand) officers and blood pressure was carried out by researchers. The results of the study were as many as $61.3 \%$ of respondents were in the SPBU environment with abnormal $(\mathrm{Pb})$ levels (> $2 \mathrm{~g} / \mathrm{m} 3), 38.7 \%$ who served in the gas station environment that had normal levels $(\mathrm{Pb})$, overall did not have hypertension Meanwhile, of the $61.3 \%$ who served in the SPBU Karya who had abnormal $(\mathrm{Pb})$ levels $(>2 \mathrm{~g} / \mathrm{m} 3)$ there were a majority of respondents who were hypertensive as many as $41.9 \%$ while the other $19.4 \%$ did not have a history of hypertension. Obtained p value $=0,000(\mathrm{p}<0.05)$, which shows that there is a relationship between the levels of $\mathrm{Pb}$ in the air the Work Environment of Operator Officers and the Occurrence of Hypertension at the Work Station. Workers should use appropriate personal protective equipment (PPE) when working and reduce smoking to inhibit lead absorption.
\end{abstract}

\section{Keywords: Plumbum levels in the Air, Hypertension, SPBU Karya}

\section{PENDAHULUAN}

Hipertensi merupakan tekanan darah persisten atau terus menerus sehingga melebihi batas normal dimana tekanan sistolik di atas $140 \mathrm{mmHg}$ dan tekanan diastoik di atas $90 \mathrm{mmHg}$, (Septi, 2014).Penyakit hipertensi merupakan gejala peningkatan tekanan darah yang kemudian berpengaruh pada organ yang lain, seperti stroke untuk otak atau penyakit jantung koroner untuk pembuluh darah untuk pembuluh darah jantung dan otot jantung. Penyakit ini menjadi salah satu masalah utama dalam ranah kesehatan masyarakat di Indonesia maupun di dunia (Ardiansyah, 2015). 
Journal of Healthcare Technology and Medicine Vol. 6 No. 2 Oktober 2020

Universitas Ubudiyah Indonesia

e-ISSN : 2615-109X

Menurut American Heart Association (AHA), penduduk Amerika yang berusia diatas 20 tahun menderita hipertensi telah mencapai angka hingga 74,5 juta jiwa, namun hampir sekitar 9095\% kasus tidak diketahui penyebabnya (Kemenkes RI, 2014). Di Indonesia masalah hipertensi cenderung meningkat. Prevalensi di perkotaan 39,9\% (37,0\% -45,8\%) dan di pedesaan 44,1 $(36,2 \%-51,7 \%)$ (Setiawan, 2012).

Menurut Djannah (2010) ada hubungan yang bermakna antara kadar timbal dengan kejadian hipertensi pada operator SPBU, dimana operator yang memiliki kadar plumbum tinggi mempunyai peluang resiko menderita hipertensi 2,619 kali lebih besar bila dibandingkan dengan operator yang memiliki kadar $\mathrm{Pb}$ rendah.

Logam $\mathrm{Pb}$ sebagai gas buangan kendaraan bermotor dapat membahayakan kesehatan dan merusak lingkungan. Logam $\mathrm{Pb}$ yang terhirup oleh manusia setiap hari akan diserap, disimpan dan kemudian ditampung dalam darah. Logam $\mathrm{Pb}$ yang terkandung dalam bensin akan mengemisikan 0,09 gram timbal tiap $1 \mathrm{~km}$. Efek yang ditimbulkan oleh Pb yaitu kemunduran IQ dan kerusakan otak yang ditimbulkan dari emisi timbal, pada orang dewasa efek yang ditimbulkan yaitupusing, kehilangan selera, sakit kepala, anemia dan tekanan darah tinggi, (Gusnita, 2012). Selain itu Efek paparan timbal pada hipertensi biasanya terjadi karena paparan kerja yang berlebihan dapat menimbulkan efek gangguan fungsi ginjal sehingga gangguan fungsi ginjal tersebut dapat berpengaruh pada tekanan darah. Timbal memiliki efek langsung dan tidak langsung pada pembuluh darah dan kontraktilitas otot polos sehingga dapat memengaruhi tekanan darah (Eka, 2017).

Berdasarkan survei awal yang dilakukan peneliti terhadap 5 orang operator SPBU, 1 orang memiliki tekanan darah 140/80mmhg, memiliki kebiasaan merokok, masa kerja diatas 2 tahun dan jenis kelamin laki-laki dan 2 orang memiliki tekanan darah 140/90 mmhg yang memiliki kebiasaan merokok dan masa kerja diatas 2 tahun dan jenis kelamin laki-laki, 1 orang memiliki tekanan darah 120/80 mmhg yang memiliki kebiasaan merokok, masa kerja di bawa 2 tahun dan jenis kelamin laki-laki, dan 1 orang yang memiliki tekanan darah 100/70 mmhg tidak mempunyai kebiasaan merokok, masa kerja dibawa 2 tahun dan jenis kelamin perempuan. Dari hasil observasi bawasanya saat bekerja para operator SPBU tidak menggunakan alat pelindung diri saat bekerja seperti masker dimana selain itu tidak adanya kebijakan dari pimpinan SPBU terhadap operator 
Journal of Healthcare Technology and Medicine Vol. 6 No. 2 Oktober 2020

Universitas Ubudiyah Indonesia

e-ISSN : 2615-109X

dengan mewajibkan menggunakan masker sehingga operator SPBU sangat mudah terpapar oleh Plumbum yang dapat mengakibatkan kejadian hipertensi.

Berdasarkan masalah di atas, maka peneliti tertarik untuk meneliti lebih lanjut tentang "Hubungan Plumbum (Pb) Di Udara Lingkungan Kerja dengan Kejadian Hipertensi Pada Operator SPBU di Kota Medan 2018.

\section{METODOLOGI PENELITIAN}

Penelitian ini bersifat deskriptif analitik dengan desain cross sectional study Populasi dalam penelitian ini adalah semua operator SPBU KARYA 14.201.145 JL. KARYA No.140 Medan yang berjumlah 31 orang dimana Teknik pengambilan sampel yang digunakan dalam penelitian ini adalah dengan cara Total Sampling.

Instrument penelitian data primer dengan mengukur tekanan darah, Pengukuran Kadar $\mathrm{Pb}$ dalam debu udarah lingkungan kerja dengan menggunakan metode AAS (Atomic Absorbtion Spektrofotometri), dengan cara debu diukur beratnya kemudian dimasukan ke dalam gelas piala 200mL. Ditambahkan $60 \mathrm{~mL} \mathrm{HCl}$ dan $5 \mathrm{~mL} \mathrm{H} 2 \mathrm{O} 2$ kemudian ditutup dengan kaca arloji. Dipanaskan hingga hampir kering, ditambahkan 5 mL H2O2 (30\%), lalu dinginkan.Disaring (gelas piala dicuci dengan aquades).Kemudian ditambahkan 2 mL HNO3 dan ditutup dengan gelas arloji, lalu dipanaskan.Dimasukkan ke gelas ukur 50mL dan dihitung dengan menggunakan AAS. Dan kemudian untuk memberikan penegasan terhadap hasil penelitian melalui lembar pedoman wawancara. Lembar pedoman wawancara digunakan untuk mengetahui umur, jenis kelamin, pendidikan, riwayat hipertensi, masa kerja dan kebiasaan merokok responden, dengan menggunakan formulir isian yang dibuat oleh peneliti untuk mengetahui karakteristik responden.

\section{HASIL DAN PEMBAHASAN}

Tabel 1. Distribusi Frekuensi Berdasarkan Karaktrisrik Responden

\begin{tabular}{clcc}
\hline Karakteristik & \multicolumn{1}{c}{ Kategori } & F & \% \\
\hline Umur & 20- 30 Tahun & 25 & 80,6 \\
& 31- 40 Tahun & 6 & 19,4 \\
\hline Jenis Kelamin & Laki-laki & 20 & 64,5 \\
\hline
\end{tabular}


Journal of Healthcare Technology and Medicine Vol. 6 No. 2 Oktober 2020

Universitas Ubudiyah Indonesia

e-ISSN : 2615-109X

\begin{tabular}{clcc}
\hline & Perempuan & 11 & 35,5 \\
\hline Pendidikan & SMP & 13 & 41,9 \\
& SMA & 18 & 58,1 \\
\hline Riwayat & Ya & 2 & $6,5 \%$ \\
Hipertensi & Tidak & 29 & $93,5 \%$ \\
\hline Masa Kerja & $<2$ Tahun & 6 & 19,4 \\
& 2-5 Tahun & 15 & 48,4 \\
& $>5$ Tahun & 10 & 32,3 \\
\hline Kebiasaan & Ya & 20 & 64,5 \\
Merokok & Tidak & 11 & 35,5
\end{tabular}

Berdasarkan tabel 1, menunjukkan bahwa mayoritas responden berumur 20 -30 tahun (80,6\%), mayoritas berjenis kelamin laki-laki $(64,5 \%)$, mayoritas memiliki pendidikan SMA $(58,1 \%)$, mayoritas tidak memiliki riwayat hipertensi $(93,5 \%)$, mayoritas memiliki masa kerja 2 5 Tahun $(48,4 \%)$, dan mayoritas memiliki kebiasaan merokok $(64,5 \%)$.

Tabel 2. Distribusi Frekuensi Berdasarkan Kadar Plumbum $(\mathrm{Pb})$

\begin{tabular}{lcc}
\hline Kadar Plumbum $(\mathbf{P b})$ & F & \% \\
\hline Normal & 12 & 38,7 \\
\hline Tidak Normal & 19 & 61,3 \\
\hline Jumlah & $\mathbf{3 1}$ & $\mathbf{1 0 0 , 0 \%}$
\end{tabular}

Berdasarkan tabel 2, menunjukkan bahwa mayoritas petugas di SPBU Karya 14.201.145Medansebanyak61,3\% berada dilingkungan SPBU dengan keadaan kadar Plumbum $(\mathrm{Pb})$ tidak normal atau melebihi ambang batas normal (>2 $\mathrm{g} / \mathrm{m} 3)$.

Tabel 3. Distribusi Frekuensi Berdasarkan Penyakit Hipertensi

\begin{tabular}{ccc}
\hline Hipertensi & F & \% \\
\hline Tidak & 18 & 58,1 \\
\hline Ya & 13 & 41,9 \\
\hline Jumlah & $\mathbf{3 1}$ & $\mathbf{1 0 0 , 0}$
\end{tabular}


Journal of Healthcare Technology and Medicine Vol. 6 No. 2 Oktober 2020

Universitas Ubudiyah Indonesia

e-ISSN : 2615-109X

Berdasarkan tabel 3, menunjukkan bahwa mayoritas responden sebanyak 58,1\% tidak menderita penyakit hipertensi (Tekanan Darah Normal).

Tabel 4. Hubungan Kadar Pb Di Udara Lingkungan Kerja Petugas Operator Dengan Kejadian Hipertensi

\begin{tabular}{|c|c|c|c|c|c|c|c|}
\hline \multirow[t]{3}{*}{ Kadar Pb } & \multicolumn{6}{|c|}{ Hipertensi } & \multirow[b]{3}{*}{$p$} \\
\hline & \multicolumn{2}{|c|}{ Tidak } & \multicolumn{2}{|c|}{$\mathbf{Y a}$} & \multicolumn{2}{|c|}{ Total } & \\
\hline & $\mathbf{f}$ & $\%$ & $\mathbf{N}$ & $\%$ & $\mathbf{F}$ & $\%$ & \\
\hline Normal & 12 & 38,7 & 0 & 0,0 & 12 & 38,7 & \\
\hline Tidak Normal & 6 & 19,4 & 13 & 41,9 & 19 & 61,3 & $\mathbf{0 , 0 0 0}$ \\
\hline Jumlah & 18 & 58,1 & 13 & 41,9 & 31 & 100,0 & \\
\hline
\end{tabular}

Berdasarkan tabel4, menunjukkan bahwa dari 12 petugas $(38,7 \%)$ yang bertugas di lingkungan SPBU Karya yang memiliki kadar Plumbum $(\mathrm{Pb})$ normal, keseluruhannya tidak memiliki penyakit hipertensi hal ini dikarenakan petugas yang berjumlah 12 orang berada di tempat pengisian bagian belakang yang hanya digunakan pada saat sift malam saja dimana pada sift malam hanya sedikit saja yang melakukan pengisian bahan bakar. Sedangkan dari 61,3\% petugas yang bertugas di lingkungan SPBU Karya yang memiliki kadar Plumbum $(\mathrm{Pb})$ tidak normal atau melebihi ambang batas normal (>2 g/m3), terdapat mayoritas responden memiliki penyakit hipertensi yaitu sebanyak 13 orang (41,9\%), sedangkan 19,4\% lainya tidak memiliki riwayat hipertensi.

\section{Kadar Plumbum Di Lingkungan SPBU Karya 14.201.145 Medan}

Plumbum $(\mathrm{Pb})$ adalah logam bersifat toksi terhadap manusia.Plumbum digunakan sebagai campuran bahan bakar bensin dan ketika bensin yang mengandung plumbum dibakar, Partikelhalus plumbum tersebut dapat langsung dihirup ke bagian paling dalam paru-paru diserap ke dalam darah dengan efisien hampir 100\%, (Dewi, 2015). 
Journal of Healthcare Technology and Medicine Vol. 6 No. 2 Oktober 2020

Universitas Ubudiyah Indonesia

e-ISSN : 2615-109X

Berdasarkan hasil penelitian yang dilakukan oleh peneliti dengan menggunakan menggunakan metode AAS (Atomic Absorbtion Spektrofotometri) yang diukur oleh Balai Riset Dan Standardisasi Industri Medan (Baristand) yang menunjukkan hasil bahwa mayoritas petugas di SPBU Karya 14.201.145 Medan sebanyak 61,3\% berada dilingkungan SPBU dengan keadaan kadar Plumbum (Pb) tidak normal atau melebihi ambang batas normal (>2 $\mathrm{g} / \mathrm{m} 3$ ).

Besarnya jumlah respoden yang berada dilingkungan SPBU dengan keadaan kadar Plumbum $(\mathrm{Pb})$ tidak normal atau melebihi ambang batas normal (>2 $\mathrm{g} / \mathrm{m} 3)$, tidak terlepas dari letak posisi kerja petugas SPBU. Pada saat penghitungan kadar plumbum di udara petugas dari Balai Riset Dan Standardisasi Industri Medan (Baristand) membagi atas 5 titik wilayah yaitu Titik 1 (Depan) yang terdiri dari 6 orang petugas memiliki nilai kadar Plumbum 6,5 g/m3,Titik 2 (Kiri) yang terdiri dari 5 orang petugas memiliki nilai kadar Plumbum 4,6 g/m3, Titik 3 (Kanan) yang terdiri dari 4 orang petugas memiliki nilai kadar Plumbum 4,8 g/m3, Titik 4 (Tengah) yang terdiri dari 4 orang petugas memiliki nilai kadar Plumbum 5,9 g/m3, Titik 5 (belakang) yang terdiri dari 12 orang petugas memiliki nilai kadar Plumbum $(\mathrm{Pb}) 1,2 \mathrm{~g} / \mathrm{m} 3$.

Berdasarkan data tersebut titik 1 sampai dengan titik 4 memiliki kadar Plumbum $(\mathrm{Pb})$ diatas nilai normal dan terdapat sebanyak 19 petugas yang berkerja di lingkungan tersebut dimana jumlah karyawan yang berada pafda titik 1 sebanyak 6 orang, pada titik 2 sebanyak 5 karyawan, pada titik 3 sebanyak 4 orang dan pada titik 4 sebanyak 4 orang karyawan. Berdasarkan pengamatan peneliti terhadap ke 5 titik lokasi atau lingkungan SPBU Karya, titik 5 yang berjumlah 12 orang karyawan sangatlah sedikit terlebih berdekatan dengan ruangan staff karyawan SPBU, sedangkan lokasi titik 1 sampai dengan titik 4 sering dilalui kendaraan bermotor untuk melakukan pengisian $\mathrm{BBM}$, hal ini tentu yang mempengaruhi peningkatan nilai kadar Plumbum $(\mathrm{Pb})$ di 4 titik lingkungan tersebut, adapun responden yang memiliki riwayat hipertensi yaitu sebanyak 2 orang yang berjenis kelamin perempuan dan laki-laki, pendidikan SMA, masa kerja 3 tahun, laki-laki memiliki kebiasaan merokok dan perempuan tidak memiliki kebiasan merokok, dari kedua responden yang memiliki riwayat hipertensi masuk ke dalam kategori kadar plumbum di udara lingkungan kerja tidak normal.

Efek paparan timbal pada hipertensi biasanya terjadi karena paparan kerja yang berlebihan dapat menimbulkan efek gangguan fungsi ginjal tersebut dapat berpengaruh pada tekanan darah.Kondisi ini perlu diantisipasi oleh petugas di SPBU Karya, sebab akan terus terpapar 
Journal of Healthcare Technology and Medicine Vol. 6 No. 2 Oktober 2020

Universitas Ubudiyah Indonesia

e-ISSN : 2615-109X

lingkungan udara dengan kadar plumbum $(\mathrm{Pb})$ yang tinggi, dan akan sangat berpengaruh bagi kesehatan para petugas tersebut.

\section{Hipertensi}

Hipertensi merupakan suatu keadaan tanpa gejala, dimana tekanan yang abnornal tinggi di dalam arteri menyebabkan meningkatnya risiko terhadap stroke, gagal jantung, serangan jantung, dan kerusakan ginjal, (Septi, 2014).Berdasarkan hasil penelitian yang dilakukan oleh peneliti yang mengukur tekanan darah setiap responden dengan menggunakan alat Tensimeter (Sphygmomanometer) dan hasil padatabel 4.3, menunjukkan bahwa mayoritas responden sebanyak 58,1\% tidak menderita penyakit hipertensi (Tekanan Darah Normal). Besarnya jumlah responden yang tidak memiliki hipertensi, tidak terlepas dari hasil penelitian dari karakteristik responden.Berdasarkan tabel 4.1, mayoritas tidak memiliki riwayat hipertensi $(93,5 \%)$ selain itu responden juga mayoritasberumur 20-30 tahun (80,6\%), tentu hal ini menjadi faktor pendukung dari jumlah mayoritas responden tidak memiliki penyakit hipertensi. Namun dengan bekerjanya responden dilingkungan yang memiliki kadar Plumbum $(\mathrm{Pb})$ yang tinggi, tentu dapat berdampak pada pada kesehatan klien terutama dengan peningkatan tekanan darah atau hipertensi Hipertensi pada dasarnya akan mengurangi harapan hidup pada para penderitanya, (Saraswati, 2016).

\section{Hubungan Kadar Plumbum (Pb) Di Udara Lingkungan Kerja Petugas Operator Dengan} Kejadian Hipertensi

Plumbum $(\mathrm{Pb})$ sangat erat kaitannya dengan peningkatan tekanan darah (Hipertensi).Sebab, pada keracunan $\mathrm{Pb}$ akut beberapa pasien menderita colic yang disertai peningkatan tekanan darah. Dari hasil uji statistik Chi-Square didapatkan $p$ value $=0,000(p$ $<0,05$ ), yang menunjukkan bahwa ada Hubungan Kadar Plumbum (Pb) Di Udara Lingkungan Kerja Petugas Operator Dengan Kejadian Hipertensi Di SPBU Karya 14.201.145 J1. Karya No.140 Medan Tahun 2018.

Berdasarkan tabel4.4, menunjukkan bahwa dari 12 orang $(38,7 \%)$ petugas yang bertugas di lingkungan SPBU Karya yang memiliki kadar Plumbum $(\mathrm{Pb})$ normal, keseluruhannya tidak memiliki penyakit hipertensi. Sedangkan dari dari 19 orang $(61,3 \%)$ petugas yang bertugas di lingkungan SPBU Karya yang memiliki kadar Plumbum $(\mathrm{Pb})$ tidak normal atau melebihi ambang batas normal (>2 g/m3), terdapat mayoritas responden memiliki penyakit hipertensi yaitu sebanyak 13 orang $(41,9 \%)$ sedangkan 6 orang $(19,4 \%)$ lainya tidak memiliki riwayat hipertensi. 
Journal of Healthcare Technology and Medicine Vol. 6 No. 2 Oktober 2020

Universitas Ubudiyah Indonesia

e-ISSN : 2615-109X

Dari data tersebut dapat disimpulkan bahwa lingkungan yang memiliki kadar Plumbum $(\mathrm{Pb})$ lebih dari nilai normal, akan mempengaruhi peningkatan tekanan darah (Hipertensi) pada responden. Sebaliknya dengan lingkungan yang memiliki kadar plumbum $(\mathrm{Pb})$ yang normal (>2 $\mathrm{g} / \mathrm{m} 3)$ akan terhindar dari resiko penyakit Hipertensi. Hasil penelitian ini juga didukung oleh penelitian yang dilakukan oleh Hasan (2012 dalam Fibrianti, 2015). Sebagai stasiun pengisian bahan bakar tentu akan banyak dilalu oleh berbagai jenis kendaraan dan Menurut Rosyidah, dkk. (2010) Dampak negatif yang didapatkan adalah tingginya tingkat polusi udara, Hasil emisi gas pembuangan kendaraan bermotor. Dengan kejadian tersebut, tentu akan mempengaruhi dengan kualitas udara dilingkungan tersebut, dan para petugas dari SPBU tentu akan menghirup unsur pb di udara lingkungan dia bekerja.Faktor pencegahan sangatlah penting, seperti penggunaan alat pelindung diri (APD) yang harus digunakan oleh para petugas SPBU seperti salah satunya penggunaan

\section{KESIMPULAN}

Mayoritas petugas di SPBU Karya 14.201.145Medansebanyak61,3\% berada dilingkungan SPBU dengan keadaan kadar Plumbum (Pb) tidak normal atau melebihi ambang batas normal (>2 $\mathrm{g} / \mathrm{m} 3$ ). Mayoritas responden sebanyak 58,1\% tidak menderita penyakit hipertensi (Tekanan Darah Normal). Terdapat hubungan Kadar Plumbum (Pb) Di Udara Lingkungan Kerja Petugas Operator Dengan Kejadian Hipertensi Di SPBU Karya 14.201.145 J1. Karya No.140 Medan Tahun 2018, dengan hasil uji statistikChi-Square didapatkan $\mathrm{p}$ value $=0,000(\mathrm{p}<0,05)$.

\section{SARAN}

Diharapkan kepada kepala operator SPBU supaya dapat menyediakan alat pelindung diri (APD) kepada petugas operator sehingga bisa membantu petugas operator tersebut terhadap halhal atau dampak polusi udara plumbum yang dapat menganggu kesehatan yaitu salah satunya dapat mengurangi kejadian hipertensi pada operator.

\section{DAFTAR PUSTAKA}

Antonin,2010,http://mathusen.wordpress.com/2010/01/24/tentang-timbal-pada-bensin/,diunduh tanggal 15 agustus 2018. Pencemaran Udara Dari Sektor Transportasi.

Ardiansyah, M. (2015).Medikal Bedah Untuk Mahasiswa. Jogjakarta: DIVA Press. 
Journal of Healthcare Technology and Medicine Vol. 6 No. 2 Oktober 2020

Universitas Ubudiyah Indonesia

e-ISSN : 2615-109X

Broker, C. (2013).Ensiklopedia Keperawatan. Editor Edisi Bahasa Indonesia EstuTiar.Jakarta: ECG.Pada Operator SPBU di Kota Kendari, 4(2).

Depkes, (2013).Sebagian Besar Penderita Hipertensi Tidak Menyadarinya, Biro Komunikasi Dan Pelayanan Masyarakat, Kementerian Kesehatan RI.

Dewi, P, Sabilu, Y, Pratiwi, A. (2015). Factor-faktor Yang Berhubungan Dengan Kadar Plumbum (Pb) Dalam Darah Pada Polisi Lalu Lintas di Kota Kendari.Jurnal Ilmiah Mahasiswa Kesehatan Masyarakat, Vol. 1 (2), 2016.

Djannah, R (2010). Hubungan Antara Kadar Pb Dalam Darah DenganKejadian Hipertensi Pada Operator SPBU Di Kota Yogyakarta.

Eka, H \& Mukono. (2017). Hubungan Kadar Timbal Dalam Darah DenganHipertensi Pekerja Pengecatan Mobil Di Surabaya, 9(1).

Febrianti, A. (2015). Karakteristik Kadar Timbal (Pb) Dalam Darah Dan Hipertensi Pekerja Home Industry Aki Bekas Di Desa Talun Kecamatan Sukodadi Kabupaten Lamongan, Jurnal Kesehatan Lingkungan. Vol 8, No.1.

Gusnita, D. (2012). Pencemaran Logam Berat Timbal (Pb) Di Udara Dan Upaya Penghapusan Bensin Bertimbal. Berita Dirgantara. Vol 13, No. 3: 95-101.

Jaishankar, K. (2014). Toxicity, mechanism and health effects of some heavy metals.Interdiscip.Toxicol. 7(2): 60-72.

Kemenkes, RI. (2014). INFODATIN.Pusat Data dan Informasi Kementerian Kesehatan RI.HIPERTENSI. Jakarta.

Kementrian Kesehatan RI. 2015. Riset Kesehatan Dasar (RISKESDAS). Jakarta: Badan Litbang Kemenkes RI.

Laode, (2017).Buku Asuhan Keperawatan Gerontik, Yogyakarta: Nuha Medika.

Muhammadun.2010. Hidup Bersama hipertensi. In Books: Yogyakarta.

Muslimah, N, dkk (2017) Hubungan Kadar Timbal dalam Darah terhadap Kejadian Hipertensi. 
Journal of Healthcare Technology and Medicine Vol. 6 No. 2 Oktober 2020

Universitas Ubudiyah Indonesia

e-ISSN : 2615-109X

Palar. H. 2012. Pencemaran dan toksikologi logam berat. Rineka cipta: Jakarta.

Pasorong, Dkk. (2014). Hubungan Antara Kadar Plumbum (Pb) Dalam Dan Hipertensi Pada Polisi Lalu Lintas Di Kota Manado. Berita Kedokteran Masyarakat. Vol. 23, No. 2.

Pratiwi, L. (2012). Perbedaan kadar Hemoglobin Darah Pada Kelompok Polisi Lalu Lintas Yang Terpapar dan Tidak Terpapar Timbal di Wilayah Polres Jakarta Selatan. Jurnal Kesehatan Masyarakat. Vol 11, No. 1:38-42.

RIKESDAS, (2015).Badan Penelitian Dan Pengembangan Kesehatan, Departemen Kesehatan, Republik Indonesia. Jakarta.

Rosyidah, H, dkk. (2010) Hubungan Antara Kadar Pb Dalam Darah DenganKejadianHipertensi Pada Operator SPBU Di Kota Yogyakarta, 4(2).

Saraswati, (2016).Diet Sehat Untuk Penyakit Asam Urat, Diabetes, Hipertensi Dan Stroke. Jogjakarta

Septi. (2014). Buku 14 Penyakit Paling Sering Menyerang dan SangatMematikan, Yogyakarta: Flashbooks.

Setiawan. (2012). Prevalens Dan Determinan Hipertensi: Depkes RI, KKP.

Siswanto., Susila., Suyanto. (2014). Metodologi Penelitian Kesehatan Dan Kedokteran. Yogyakarta: Salemba Medika.

Smeltzer, S, B. (2015) Buku Ajar Keperawatan Medical Bedah. Edisi 8.Vol 2. Jakarta: Penerbit Buku kedokteran Indonesia ECG.

Soemirat.(2014). Kesehatan Lingkungan. Yogyakarta: Gadjah Mada University Press.

Triyanto, Endang. (2014). Pelayanan Keperawatan Bagi Penderita Hipertensi Secara Terpadu. Yogyakarta: Graha Ilmu.

World Health Organization. A global brief on hypertension: silent killer, global public health crisis. 2015. 